\title{
GCU
}

Glasgow Caledonian

University

University for the Common Good

\section{Results from the third Scottish National Prevalence Survey: is a population health approach now needed to prevent healthcare-associated infections?}

Cairns, S; Gibbons, C; Milne, A; King, H; Llano, M; MacDoanld, L; Malcolm, William;

Robertson, Chris; Sneddon, J; Weir, J; Reilly, J

Published in:

Journal of Hospital Infection

DOI:

10.1016/j.jhin.2018.03.038

Publication date:

2018

Document Version

Author accepted manuscript

Link to publication in ResearchOnline

Citation for published version (Harvard):

Cairns, S, Gibbons, C, Milne, A, King, H, Llano, M, MacDoanld, L, Malcolm, W, Robertson, C, Sneddon, J, Weir, $\mathrm{J} \&$ Reilly, J 2018, 'Results from the third Scottish National Prevalence Survey: is a population health approach now needed to prevent healthcare-associated infections?', Journal of Hospital Infection, vol. 99, no. 3, pp. 312317. https://doi.org/10.1016/j.jhin.2018.03.038

\section{General rights}

Copyright and moral rights for the publications made accessible in the public portal are retained by the authors and/or other copyright owners and it is a condition of accessing publications that users recognise and abide by the legal requirements associated with these rights.

Take down policy

If you believe that this document breaches copyright please view our takedown policy at https://edshare.gcu.ac.uk/id/eprint/5179 for details of how to contact us. 


\section{Summary}

\section{Background}

Healthcare associated infections $(\mathrm{HAl})$ are a major public health concern and a significant cause of morbidity and mortality. A robust and current evidence base that is specific to local, national and Europe-wide settings is necessary to inform the development of strategies to reduce $\mathrm{HAl}$ and contain antimicrobial resistance (AMR).

$\underline{\text { Aim }}$

To measure the prevalence of $\mathrm{HAI}$ and antimicrobial prescribing and identify key priority areas for interventions to reduce the burden of infection.

\section{Methods}

A national rolling PPS in National Health Service (NHS) acute, NHS non-acute, NHS paediatric and independent hospitals was carried out between September and November 2016 using the European Centre for Disease Prevention and Control protocol designed for the European PPS.

\section{Findings}

The prevalence of $\mathrm{HAl}$ was $4.6 \%, 2.7 \%$ and $3.2 \%$ in acute adults, paediatric and non-acute patient groups, respectively. The most common HAI types reported in adult patients were urinary tract infection and pneumonia. The prevalence of antimicrobial prescribing was $35.7 \%, 29.3 \%$ and $13.8 \%$ in acute adults, paediatric and non-acute patient groups, respectively. Respiratory, skin and soft tissue, gastrointestinal and urinary tract infections were the most common infections being treated at the time of survey.

\section{Conclusion}

HAI continues to be a public health concern in Scotland. UTI and pneumonia continue to place a significant burden on patients and on healthcare delivery, including those that develop in the community and require hospital admission. $A$ broader population health approach which focuses on reducing the risk of infection upstream would reduce these infections in both community and hospital settings. 


\section{Introduction}

Healthcare associated infections $(\mathrm{HAI})$ are a major public health concern and a significant cause of morbidity and mortality globally. ${ }^{1}$ The European Centre for Disease Prevention and Control (ECDC) estimates that 3.2 million patients develop a $\mathrm{HAl}$ every year in Europe. ${ }^{2}$ A significant proportion of $\mathrm{HAl}$ are considered to be avoidable and prevention of these infections provides an opportunity to improve patient outcome and reduce unnecessary costs within healthcare systems. ${ }^{3}$

A robust and current evidence base that is specific to local, national and Europewide settings is necessary to inform the development of strategies to reduce $\mathrm{HAl}$ and contain antimicrobial resistance $(\mathrm{AMR}) .{ }^{4}$ In response to a European Union (EU) Council Recommendation on patient safety, including prevention and control of $\mathrm{HAI}^{5}$, ECDC developed a standardised point prevalence survey (PPS) protocol which has been used in two Europe-wide PPS. ${ }^{6}$

National PPS are undertaken every five years in Scotland in order to take stock of the current epidemiological situation and to review local and national policy. To date, there have been three national PPS undertaken in Scotland; 2005/6 ${ }^{7}, 2011^{8}$ and 2016. ${ }^{9}$ Both of the latter surveys were undertaken using the ECDC protocol and contributed to the Europe-wide surveys. The results from the third Scottish PPS will inform the development of key priority areas and recommendations for the prevention and control of infection and antimicrobial stewardship programmes.

This paper describes the headline results from the Scottish 2016 PPS, focusing on urinary tract infections and pneumonia, and highlights the need for a broader public health approach for prevention of infection across all settings. 


\section{Methods}

Study design

A rolling point prevalence survey was carried out in Scottish hospitals during September, October and November 2016. The Scottish protocol was developed using the ECDC protocol for PPS. ${ }^{6}$ The survey included all National Health Service (NHS) acute, NHS paediatric and independent hospitals, and a $25 \%$ sample of NHS non-acute hospitals.

Data were collected by trained teams of staff from local Infection Prevention and Control Teams (IPCT) and Antimicrobial Management Teams (AMT). Data were extracted from a number of sources available on the ward at the time of survey. The ECDC case definitions for HAl were used. ${ }^{6}$ Full details of the study design and data collection methods are provided in the Scottish PPS protocol. ${ }^{10}$

Analysis

The acute and paediatric surveys of all hospitals were analysed as cluster samples with wards nested within hospitals. The non-acute survey was a stratified (psychiatry/non-psychiatry) cluster sample with hospitals selected in proportion to size within each stratum. Sample weights were also used in the non-acute survey to compensate for under-sampling in the psychiatry strata as low prevalence was anticipated and there were large hospitals in this stratum. The prevalence of HAl in the acute adult inpatient sample was also stratified by hospital type according to ECDC definitions (primary, secondary specialised and tertiary). ${ }^{6}$ Survey mean clustered $\mathrm{Cl}$ were used when the sample size was large (acute adult patient group and total acute hospital population).Wilson's unadjusted confidence intervals ( $\mathrm{Cl})$ were used when the prevalence was low and the sample size small (paediatric and non-acute patient groups). Statistical analysis was carried out using $\mathrm{R}$ version 3.3.1 and the 'survey' library. ${ }^{11}$ 
A gold standard validation study was carried out concurrently with the national PPS using the Scottish PPS validation protocol which was based on the ECDC PPS Validation Protocol. ${ }^{12}$ The sensitivity and specificity for the presence of $\mathrm{HAl}$ and antimicrobials were calculated with $95 \% \mathrm{Cl}$.

Extrapolation of the gold standard validation results to HAI prevalence

The results from the gold standard validation were used to calculate an adjusted prevalence of HAl that accounted for possible under- or over-reporting by the local data collection teams. The sensitivity and specificity were used to adjust the prevalence and bootstrapping methods were used to calculate the $95 \% \mathrm{Cl}$ around the adjusted prevalence. The bootstrapping methods accounted for sampling variation in the sensitivity/specificity estimates and the prevalence estimate.

\section{Estimation of the burden of $\mathrm{HAl}$}

The ECDC methodology for calculating the burden of HAI was used to estimate the burden of HAI. ${ }^{2}$ The Rhame and Sudderth equation ${ }^{13}$ was applied to the prevalence figure adjusted to control for the potential under-reporting identified by the gold standard validation:

Incidence $=$ prevalence ${ }^{*}($ length of stay $/($ date of survey - date of onset $))$

The average length of stay in Scottish acute adult patients was estimated using data from national datasets. ${ }^{14}$ The mean and median difference between date of onset of $\mathrm{HAl}$ and date of survey were used in the equation. The incidence calculated using the mean and the median was averaged. The resulting incidence was then applied to the annual number of acute adult inpatient stays to estimate the number of HAI per year in acute adult inpatients in Scotland. The 95\% confidence interval was 
calculated using bootstrapping methods to propagate the uncertainty from the prevalence adjustment that was based on the gold standard validation results. 
A total of 11627 acute hospital patients (acute, paediatric and independent hospitals) and 1083 non-acute hospital patients were included in the survey. The median ages of patients surveyed in acute and non-acute hospitals were 71 years (range 0 to 102, inter-quartile range (IQR) 52 to 82) and 80 years (range 17 to 104, IQR 69 to 87), respectively. Two fifths of patients surveyed in acute hospitals $(40.0 \%, n=4609)$ and $65.7 \%$ in non-acute hospitals $(n=697)$ had the most severe comorbidity scores (ultimately fatal or rapidly fatal McCabe ${ }^{15}$ score).

Prevalence of HAI

The prevalence of HAI by patient group and by hospital type in the acute adult population is described in Table I. The distributions of HAl types in the four patient groups are described in Table II. A total of $527 \mathrm{HAl}$ occurring in 497 acute adult inpatients, $20 \mathrm{HAl}$ in 20 paediatric inpatients and $34 \mathrm{HAl}$ in 34 non-acute inpatients were reported. The causative micro-organisms are described in Table III. A total of 323 of the HAI met the case definition without positive microbiology at the time of survey $(55.6 \%)$.

Prevalence of antimicrobial prescribing

The prevalence of antimicrobial prescribing by patient group is described in Table IV. A total of 6381 antimicrobials were prescribed in the surveyed patients. The distributions of the types of infections being treated at the time of survey are described in Table $\mathrm{V}$. 
A total of 258 patients in nine hospitals were included in the gold standard validation exercise. Ten of the included patients had a HAl and 109 patients were receiving antimicrobials at the time of survey. The sensitivity and specificity of the HAl data item were $60 \%$ (95\% Cl: 31.3 to 83.2$)$ and 100\% (95\% Cl: 98.5 to 100), respectively. The sensitivity and specificity of the antimicrobial data were $89.0 \%$ (95\% Cl: 81.7 to 93.6) and $97.8 \%$ (95\% Cl: 93.8 to 99.6$)$, respectively.

Extrapolation of the gold standard validation results to HAI prevalence

The sensitivity was used to adjust the reported prevalence of HAI in acute adult patients by assuming that the false negative rate was $40 \%$ in the primary data collection. As the specificity was $100 \%$, no adjustment for the false positive rate was undertaken. The prevalence before adjustment was $4.6 \%$ and after adjustment for the estimated under-reporting was $7.7 \%(95 \% \mathrm{Cl}: 5.1$ to 15.8$)$.

Burden of HAI

The incidence of HAI was calculated using the mean and median duration between date of onset and date of survey; 7.6 days and 5 days, respectively. The estimated length of stay in acute adult inpatients was 6.7 days. ${ }^{14}$ The estimated prevalence was calculated using the adjusted prevalence (7.7\%). The incidences of HAI calculated using the mean and median duration were $6.7 \%$ and $10.2 \%$, respectively and the average incidence was $8.4 \%$. Application of the incidence to the number of hospital stays in Scotland $(n=655$ 061), resulted in an estimate that there are 55307 $\mathrm{HAl}$ in acute adult inpatients each year in Scotland (95\% Cl: 35000 to 108 000). 


\section{Discussion}

The third Scottish national PPS reported that, whilst the prevalence of HAI was significantly lower in acute adult inpatients than in 2011 (4.6\% versus 5.0\%, $\mathrm{p}=0.03)^{8 ; 9}$, there is still a high burden of HAl in Scottish acute hospitals wherein one in 22 patients $(4.5 \%)$ at any one time have an HAl. This is equivalent to one patient on every ward, every day, in every acute hospital in Scotland with an infection associated with the care they have received in hospital. A gold standard validation study identified likely under-reporting of HAl and after adjustment to account for this, the prevalence was estimated to be $7.7 \%$. This accounts for an estimated 55500 HAl per year in acute adult patients in Scotland.

The patient population is older and sicker than five years ago ${ }^{8 ; 9}$ and this has important implications for the risk of HAI. These differences likely reflect the continuing change in the demographics of the general population. The number of people aged 75 years and over in Scotland is projected to increase by approximately $29 \%$ between 2014 and $2024 .^{16}$ The changing demographics of the population has important implications for infection risk, including the risk of HAl, with older patients at an increased risk of developing infection, both in hospital and in the community. ${ }^{17-}$ 19

The most common HAl types differed between adult and paediatric patients and this reflects differences in risk in these patient groups. In paediatric patients, the epidemiological picture of clinical sepsis and bloodstream infection is similar to that reported in Scotland and more widely across Europe during the 2011 PPS. ${ }^{2 ; 8}$ An epidemiological review of all of the European paediatric data collected during the 2011/12 survey recommended that infection prevention and control strategies should focus on prevention of BSI, particularly among neonates and infants. ${ }^{20}$ The most common $\mathrm{HAI}$ (UTI and pneumonia) reported in the adult patients in this survey reflect the elderly population in acute and non-acute hospital settings. These HAI were also the most commonly reported in the 2011 Scottish and European surveys ${ }^{2 ; 8}$ confirming the continuing need for focused action to tackle the burden of these infections. Importantly, this survey has identified that a significant proportion of these infections were not associated with the use of invasive devices. ${ }^{9}$ Traditionally, interventions to prevent UTI and pneumonia in healthcare settings have focused on 
catheter associated urinary tract infections and ventilator associated pneumonia. A recent review of guidance and literature relating to pneumonia in non-ventilated patients reported that there was a lack of evidence for preventative measures and no specific national guidance had been issued by professional societies or professional medical associations for the prevention of these infections. ${ }^{21}$ The main focus of the current National Institute for Health and Care Excellence (NICE) guideline is the management of community acquired pneumonia rather than prevention. ${ }^{22}$ The development of national multimodal programmes for the prevention of pneumonia and urinary tract infections across all healthcare settings has the potential for significant impact. ${ }^{23 ; 24}$ These programmes should include the development of new targeted IPC interventions such as guidelines and quality improvement tools; strengthen IPC and stewardship across all healthcare settings; and promote broader public health interventions, such improving hydration, nutrition ${ }^{25 ; 26}$ and mobilisation $^{21}$, in order to reduce the risk of infection in the older population.

The types of HAl reported are commonly associated with Gram negative organisms where the greatest threat of AMR currently lies. E. coli, for the first time, was the most commonly reported causative organism. This is a change from the last two PPS in Scotland wherein $S$. aureus was the most frequently reported. ${ }^{8 ; 9}$ Preventing the spread of these micro-organisms in hospital settings is an essential component of controlling antimicrobial resistance alongside protecting and stewarding the use of antimicrobials. $^{27-29}$

More than a third of acute adults inpatients were receiving one or more antimicrobials and this was higher than five years ago after accounting for differences in patient case mix (35.7\% versus $33.2 \%, p=0.01) .{ }^{8 ; 9}$ Importantly, this survey highlights that the types of infection occurring in Scottish hospitals were also associated with a large burden of prescribing to treat community acquired infection in hospital. Reducing the risk of developing UTI and pneumonia in the older population both before and during hospital admissions would reduce the burden that these infections place on the healthcare system as a whole and prevent the unnecessary use of antimicrobials. 
There are methodological limitations to prevalence surveys that must be acknowledged. Prevalence surveys represent only the time of survey and the cross sectional approach is biased towards identifying $\mathrm{HAl}$ of longer duration and patients with a longer length of stay are overrepresented in prevalence surveys. The adjustment of $\mathrm{HAl}$ prevalence using the results from the gold standard validation was based on a small number of validated HAI. The prevalence of HAI in the primary survey and the validation survey differed and this may have affected the extrapolation as the predictive values may be different in the primary survey. In addition, the burden calculation was based on single parameters whilst previous calculations, including those used in the previous ECDC survey ${ }^{2}$, were based on modelled parameters.

In conclusion, the results from this third national PPS highlight the continuing burden that UTI and pneumonia are placing on hospitals including those developing in the community requiring admission. Given the changes to the way care is delivered and will be delivered in the future ${ }^{30}$, it is appropriate that a population health approach which includes both IPC and broader public health interventions, and focuses on reducing the risk of infection upstream, before admission to hospital, is developed. Such an approach would reduce community acquired infections and the associated prescribing and risk of AMR; reduce the need for hospital admission for infections and reduce the risk of patients developing a HAI should they require to be admitted to hospital.

\section{Acknowledgements}

This survey would not have been completed successfully and within schedule without the cooperation and support of local Infection Control and Antimicrobial Management Teams in all of the participating hospitals. Their collaboration is gratefully acknowledged.

\section{Conflict of Interests}

None declared. 
Source of Funding

This project was funded by the Scottish Government. 


\section{References}

1. World Health Organization. Report on the Burden of Endemic Health CareAssociated Infection Worldwide. Geneva: WHO; 2011.

2. European Centre for Disease Prevention and Control. Point prevalence survey of healthcare-associated infection and antimicrobial use in European acute care hospitals 2011- 2012. Stockholm: ECDC; 2013.

3. Harbarth S, Sax H, Gastmeier P. The preventable proportion of nosocomial infections: an overview of published reports. J Hosp Infect 2003;54:258-66.

4. Reilly J, Stewart S, Allardice G, Cairns S, Ritchie L, Bruce J. Evidence-based infection control planning based on national healthcare-associated infection prevalence data. Infect Control Hosp Epidemiol 2009;30:187-189

5. European Commission. Council Recommendation on patient safety, including the prevention and control of healthcare associated infections (2009/C 151/01). Brussels: European Council; 2009.

6. European Centre for Disease Prevention and Control. Point prevalence survey of healthcare-associated infections and antimicrobial use in European acute care hospitals - protocol version 5.3. Stockholm: ECDC; 2015.

7. Health Protection Scotland. NHS Scotland National HAI Prevalence Survey. Final Report 2007. Glasgow: HPS; 2007.

8. Health Protection Scotland. Scottish National Point Prevalence Survey of Healthcare Associated Infection and Antimicrobial Prescribing 2011. Glasgow: HPS; 2012.

9. Health Protection Scotland. National Point Prevalence Survey of Healthcare Associated Infection and Antimicrobial Prescribing 2016. Glasgow: HPS; 2017.

10. Health Protection Scotland. Point Prevalence Survey of Healthcare Associated Infection and Antimicrobial Prescribing 2016: Protocol for the collection of patient and ward level data. Glasgow: HPS; 2016.

11. Lumley T. Analysis of Complex Survey Samples. J. Stat. Softw 2004:1;1-19. 
12. European Centre for Disease Prevention and Control. Point prevalence survey of healthcare associated infections and antimicrobial use in European acute care hospitals. PPS Validation Protocol Version 3.1. Stockholm: ECDC; 2015.

13. Rhame FS, Sudderth WD. Incidence and prevalence as used in the analysis of the occurrence of nosocomial infections. Am J Epidemiol 1981;113:1-11.

14. Information Services Division. Average length of stay in hospital, by admission type and specialty, Scotland. Edinburgh: ISD; 2016.

15. McCabe WR, Jackson GG. Gram-negative bacteraemia. Etiology and ecology. Arch Intern Med 1962;110:845

16. National Records of Scotland. Projected Population of Scotland (2014-based). Edinburgh: NRS; 2015.

17. Paillaud E, Herbaud S, Caillet P, Lejonc JL, Campillo B, Bories PN. Relations between undernutrition and nosocomial infections in elderly patients. Age Ageing 2005;34:619-25.

18. Parker SG, Fadayevatan R, Lee SD. Acute hospital care for frail older people. Age Ageing 2006;35:551-2.

19. Strausbaugh LJ. Emerging health care-associated infections in the geriatric population. Emerg Infect Dis 2001;7:268-71.

20. Zingg W, Hopkins S, Gayet-Ageron A, et al. Health-care-associated infections in neonates, children, and adolescents: an analysis of paediatric data from the European Centre for Disease Prevention and Control point-prevalence survey. Lancet Infect Dis 2017;17:01.

21. Passaro L, Harbarth S, Landelle C. Prevention of hospital-acquired pneumonia in non-ventilated adult patients: a narrative review. Antimicrob Resist Infect Control 2016;5:43-54.

22. National Institute for Health and Care Excellence. Pneumonia in adults: diagnosis and management. London: NICE; 2014. 
23. Zingg W, Holmes A, Dettenkofer M, Goetting T, Secci F, Clack L, et al. Hospital organisation, management, and structure for prevention of health-careassociated infection: A systematic review and expert consensus. Lancet Infect Dis $2015 ; 15: 212-224$

24. Montoya A, Cassone M, Mody L. Infections in Nursing Homes: Epidemiology and Prevention Programs. Clin Geriatr Med 2016;32:585-607.

25. Healthcare Improvement Scotland. Food, Fluid and Nutritional Care Standards. Glasgow: HIS; 2014.

26. Department of Health. The Hospital Food Standards Panel's report on standards for food and drink in NHS hospitals. London: Department of Health; 2014.

27. World Health Organization. Global Action Plan on Antimicrobial Resistance. Geneva: WHO; 2015.

28. Public Health England. UK Five Year Antimicrobial Resistance Strategy 2013 to 2018. London: PHE; 2013.

29. Wilson APR, Livermore DM, Otter JA, et al. Prevention and control of multidrug-resistant Gram-negative bacteria: recommendations from a Joint Working Party. J Hosp Infect 2016;92:S1-S44.

30. National Audit Office. Health and social care integration. London: NAO; 2017. 
Table I: Prevalence of HAI in Scotland in 2016, by patient group

\begin{tabular}{|c|c|c|c|c|c|}
\hline Patient group & $\begin{array}{c}\text { Number of patients } \\
\text { surveyed }^{*}\end{array}$ & $\begin{array}{l}\text { Number of } \\
\text { patients } \\
\text { with HAI }\end{array}$ & $\begin{array}{l}\text { Prevalence } \\
\text { (\%) }\end{array}$ & $\begin{array}{c}95 \% \\
\text { Lower Cl }\end{array}$ & $\begin{array}{c}95 \% \text { Upper } \\
\text { Cl }\end{array}$ \\
\hline $\begin{array}{l}\text { Acute adult } \\
\text { patients }\end{array}$ & 10813 & 497 & 4.6 & 4.1 & 5.1 \\
\hline Primary & 682 & 32 & 4.7 & 3.3 & 6.5 \\
\hline Secondary & 5133 & 214 & 4.2 & 3.7 & 4.8 \\
\hline Specialised & 253 & 7 & 2.8 & 1.3 & 5.6 \\
\hline Tertiary & 4745 & 244 & 5.1 & 4.5 & 5.8 \\
\hline Paediatric patients & 734 & 20 & 2.7 & 1.8 & 4.2 \\
\hline $\begin{array}{l}\text { Total acute } \\
\text { patients }\end{array}$ & 11547 & 517 & 4.5 & 4 & 5 \\
\hline Non-acute patients & 1079 & 34 & 3.2 & 2.3 & 4.4 \\
\hline
\end{tabular}

* Number of patients surveyed with HAI status recorded. HAI data for acute adult, paediatric and non-acute patients were not recorded for 76,4 and 4 patients, respectively 
Table II: Distribution of HAl types in Scotland in 2016, by patient group

\begin{tabular}{|l|c|c|c|c|c|c|}
\hline \multirow{2}{*}{\multicolumn{1}{|c|}{ HAI Type }} & \multicolumn{2}{c|}{$\begin{array}{c}\text { Acute adult } \\
\text { patients }\end{array}$} & \multicolumn{2}{c|}{$\begin{array}{c}\text { Paediatric } \\
\text { patients }\end{array}$} & \multicolumn{2}{c|}{$\begin{array}{c}\text { Non-acute adult } \\
\text { patients }\end{array}$} \\
\cline { 2 - 7 } & $\mathbf{N}$ & $\mathbf{\%}$ & $\mathbf{N}$ & $\mathbf{\%}$ & $\mathbf{N}$ & $\%$ \\
\hline Urinary tract infection & 129 & 24.5 & 0 & 0.0 & 20 & 58.8 \\
\hline Pneumonia & 118 & 22.4 & 2 & 10.0 & 4 & 11.8 \\
\hline Surgical site infection & 87 & 16.5 & 2 & 10.0 & 3 & 8.8 \\
\hline Laboratory-confirmed BSI & 46 & 8.7 & 4 & 20.0 & 1 & 2.9 \\
\hline Skin and soft tissue infection & 38 & 7.2 & 1 & 5.0 & 2 & 5.9 \\
\hline $\begin{array}{l}\text { Eye, ear, nose, throat or mouth } \\
\text { infection }\end{array}$ & 29 & 5.5 & 0 & & 0 & 0.0 \\
\hline Gastrointestinal tract infection & 27 & 5.1 & 2 & 10.0 & 2 & 5.9 \\
\hline Systemic infection & 17 & 3.2 & 9 & 45.0 & 1 & 2.9 \\
\hline CVC/PVC related infection & 16 & 3.0 & 0 & 0.0 & 0 & 0.0 \\
\hline $\begin{array}{l}\text { Lower respiratory tract } \\
\text { infection, other than } \\
\text { pneumonia }\end{array}$ & & & 0 & & 1 & 2.9 \\
\hline Bone/joint infection & 8 & 1.5 & & 0.0 & & \\
\hline $\begin{array}{l}\text { Cardiovascular system } \\
\text { infection }\end{array}$ & 4 & 0.8 & 0 & 0.0 & 0 & 0.0 \\
\hline $\begin{array}{l}\text { Central nervous system } \\
\text { infection }\end{array}$ & 4 & 0.8 & 0 & 0.0 & 0 & 0.0 \\
\hline Reproductive tract infection & 2 & 0.4 & 0 & & 0 & 0.0 \\
\hline Total & 2 & 0.4 & 0 & 0.0 & 0 & 0.0 \\
\hline
\end{tabular}


Table III: Distribution of reported causative micro-organisms in Scotland in 2016, by patient group

\begin{tabular}{|l|c|c|c|c|c|c|}
\hline \multirow{2}{*}{ Micro-organism } & \multicolumn{2}{|c|}{ Acute Adults } & \multicolumn{2}{c|}{ Paediatric } & \multicolumn{2}{c|}{ Non-acute adults } \\
\cline { 2 - 7 } & $\mathbf{N}$ & $\mathbf{\%}$ & $\mathbf{N}$ & $\mathbf{\%}$ & $\mathbf{N}$ & $\%$ \\
\hline Escherichia coli & 64 & 22.7 & 2 & 25.0 & 11 & 61.1 \\
\hline Staphylococcus aureus & 57 & 20.2 & 2 & 25.0 & 2 & 11.1 \\
\hline Clostridium difficile & 15 & 5.3 & 0 & 0.0 & 1 & 5.6 \\
\hline Enterococcus faecalis & 10 & 3.6 & 2 & 25.0 & 0 & 0.0 \\
\hline Klebsiella pneumoniae & 10 & 3.6 & 0 & 0.0 & 1 & 5.6 \\
\hline Klebsiella oxytoca & 9 & 3.2 & 0 & 0.0 & 0 & 0.0 \\
\hline Aspergillus niger & 8 & 2.8 & 0 & 0.0 & 0 & 0.0 \\
\hline Enterococcus faecium & 8 & 2.8 & 0 & 0.0 & 0 & 0.0 \\
\hline Anaerobes, not specified & 7 & 2.5 & 0 & 0.0 & 0 & 0.0 \\
\hline Candida species, not specified & 7 & 2.5 & 0 & 0.0 & 0 & 0.0 \\
\hline Staphylococcus epidermidis & 7 & 2.5 & 1 & 12.5 & 0 & 0.0 \\
\hline Haemophilus influenzae & 6 & 2.1 & 0 & 0.0 & 0 & 0.0 \\
\hline Proteus mirabilis & 6 & 2.1 & 0 & 0.0 & 1 & 5.6 \\
\hline Pseudomonas aeruginosa & 6 & 2.1 & 0 & 0.0 & 1 & 5.6 \\
\hline Other & 62 & 22.0 & 1 & 12.5 & 1 & 5.6 \\
\hline Total & $\mathbf{2 8 2}$ & $\mathbf{1 0 0 . 0}$ & $\mathbf{8}$ & $\mathbf{1 0 0 . 0}$ & $\mathbf{1 8}$ & $\mathbf{1 0 0 . 0}$ \\
\hline
\end{tabular}

*In acute adult patients, the "Other" group included 62 reports with less than five reports per microorganism, of which $30.6 \%$ were Gram negative bacilli 
Table IV: Prevalence of antimicrobial prescribing in Scotland in 2016, by patient group

\begin{tabular}{|l|c|c|c|c|c|}
\hline Patient group & $\begin{array}{c}\text { Number of } \\
\text { patients } \\
\text { surveyed* }\end{array}$ & $\begin{array}{c}\text { Number of patients } \\
\text { receiving an } \\
\text { antimicrobial }\end{array}$ & $\begin{array}{c}\text { Prevalence } \\
\text { (\%) }\end{array}$ & $\begin{array}{c}\mathbf{9 5 \%} \\
\text { Lower } \\
\text { Cl }\end{array}$ & $\begin{array}{c}\mathbf{9 5 \%} \\
\text { Upper } \\
\text { Cl }\end{array}$ \\
\hline Acute adult patients & 10869 & 3878 & 35.7 & 34.2 & 37.2 \\
\hline Paediatric patients & 736 & 216 & 29.3 & 26.2 & 32.7 \\
\hline Total acute patients & $\mathbf{1 1 6 0 5}$ & $\mathbf{4 0 9 4}$ & $\mathbf{3 5 . 3}$ & $\mathbf{3 3 . 8}$ & $\mathbf{3 6 . 7}$ \\
\hline Non-acute patients & 1074 & 148 & 13.8 & 11.8 & 16.0 \\
\hline
\end{tabular}

* Number of patients surveyed with antimicrobial status recorded. Antimicrobial data for acute adult, paediatric and non-acute patients were not recorded for 20, 2 and 9 patients, respectively 
Table V: Distribution of diagnoses for treatment of infection prescribing in Scotland in 2016, by patient group

\begin{tabular}{|l|c|c|c|c|c|c|}
\hline \multirow{2}{*}{ Diagnosis } & \multicolumn{2}{|c|}{} & \multicolumn{2}{c|}{} & \multicolumn{2}{c|}{$\begin{array}{c}\text { Non-acute } \\
\text { patients }\end{array}$} \\
\cline { 2 - 7 } & Acute adult patients & Paediatric patients & N & $\%$ \\
\hline Respiratory & $\mathbf{N}$ & $\mathbf{\%}$ & $\mathbf{N}$ & $\mathbf{\%}$ & $\mathbf{N}$ & $\mathbf{2}$ \\
\hline Skin and soft tissue & 1665 & 35.3 & 49 & 19.8 & 33 & 28.9 \\
\hline Gastrointestinal & 828 & 17.5 & 21 & 8.5 & 30 & 26.3 \\
\hline Urinary tract & 727 & 15.4 & 23 & 9.3 & 1 & 0.9 \\
\hline Systemic & 651 & 13.8 & 18 & 7.3 & 41 & 36.0 \\
\hline Ear, nose, throat & 441 & 9.3 & 102 & 41.3 & 3 & 2.6 \\
\hline Other/unspecified & 170 & 3.6 & 15 & 6.1 & 2 & 1.8 \\
\hline Cardiovascular & 86 & 1.8 & 5 & 2.0 & 3 & 2.6 \\
\hline Genitourinary & 58 & 1.2 & 0 & 0.0 & 0 & 0.0 \\
\hline Central nervous system & 53 & 1.1 & 1 & 0.4 & 1 & 0.9 \\
\hline Eye & 36 & 0.8 & 13 & 5.3 & 0 & 0.0 \\
\hline Not recorded & 3 & 0.1 & 0 & 0.0 & 0 & 0.0 \\
\hline Total & 2 & 0.1 & 0 & 0.0 & 1 & 0.0 \\
\hline
\end{tabular}

